\title{
K-12 TEACHERS' PERCEPTIONS OF STEM
}

\author{
Brittany Vancil, M.S., Teacher, Rosedale Elementary, brittany.vancil@gmail.com \\ Emily Nicholson, M.S., Teacher, American School Fdn of Monterrey, emily.j.nicholson@gmail.com
}

\begin{abstract}
Integrated Science, Technology, Engineering, and Math (STEM) has been a recent trend in education. We set out to understand how K-12 teachers define STEM, their comfort level with teaching STEM, perspectives on the pros and cons of STEM, and the teaching tools and platforms they use. Our research concludes with the implications for teachers, administrators, curriculum developers, and researchers, as well as helpful resources.
\end{abstract}

\section{Introduction}

As graduate students in a program with a concentration in integrated STEM, we were intrigued by our peers' perceptions of integrated STEM teaching. The goal of this project was to identify and analyze integrated STEM perceptions from a large population of teachers to see if there were any recurring trends or patterns.

\section{Methods and Results}

We surveyed 144 teachers who taught various subjects and grade levels. The survey was a combination of open-ended, multi-select, and Likert scale questions. Results from the survey were then analyzed using a natural language processing approach called TF*IDF (term frequency*inverse document frequency). Multiple relational analyses were run comparing the demographics of survey respondents to trends in their overall responses. As we looked to understand teachers' perceptions about teaching integrated STEM along with the relationship between respondent's demographics and reported comfort teaching STEM, it came as no surprise that the more lessons taught, the more comfortable teachers were teaching them. Respondents overwhelmingly agreed that integrated STEM helped students to make connections between disciplines, primarily science and math. Though there are nine generally recognized definitions of STEM, survey respondents tended to gravitate towards defining STEM as a combination of all four subjects taught in a context requiring real-world applications (Bybee, 2013, p. 74-79). Teachers indicated that time and materials were extensive limiters to teaching integrated STEM lessons. Additionally, many felt there was a lack of priority on STEM from their school districts, and many teachers indicated not feeling knowledgeable enough to teach STEM. Due to the COVID-19 pandemic, respondents also shared a concern about following restrictive guidelines in their classrooms.

\section{Discussion}

The results of this study were consistent with prior research, with a major takeaway being that teachers felt that students seemed more engaged in and reaped more benefits from courses that took a hands-on, integrated STEM approach, as supported in Berland \& Steingut, 2016. A commonly requested improvement for promoting and advancing integrated STEM was a centralized database of general STEM teaching resources. Survey respondents were limited to current K-12 teachers, mostly of STEM fields. A wider-reaching survey amongst teachers would help inform further discussion, as would a survey amongst students and parents. However, we do feel that data gathered from this initial survey is beneficial for school administrators to begin making changes in their corporations to help teachers have the time, materials, resources, and training needed to feel confident in teaching integrated STEM.

\section{References}

Berland, L. K., \& Steingut, R. (2016). Explaining variation in student efforts towards using math and science knowledge in engineering contexts. International Journal of Science Education, 38(18), 2742-2761 Bybee, R.W. The case for STEM education: Challenges and opportunities. NSTA, 2013. 